\title{
AS RELIGIÕES DE MATRIZ AFRICANA E INTOLERÂNCIA RELIGIOSA
}

\section{AFRICAN-BASED RELIGIONS AND RELIGIOUS INTOLECANCE}

\author{
Kabengele Munanga ${ }^{1}$
}

\begin{abstract}
Resumo
O objetivo deste artigo é fazer alguma reflexão crítica sobre as violências que permeiam a trajetória da população negra no Brasil, desde o tráfico humano transatlântico até os dias atuais, tendo como principal enfoque a discriminação religiosa embutida no racismo à brasileira, que impacta as religiões de matriz africana, em diferentes contextos, tornando-as alvo de perseguições e campanhas de destruição.
\end{abstract} Surpreendentemente, essas religiões resistiram, sobreviveram e se tornaram religiões brasileiras aceitas e

\footnotetext{
${ }^{1}$ Brasileiro por naturalização desde 1985, Kabengele Munanga nasceu na República Democrática do Congo, onde se graduou em Antropologia Social e Cultural pela Universidade Oficial do Congo (1964-1969). Foi nessa Universidade que iniciou sua carreira acadêmica como Professor Assistente (1969-1975). Em 1969 recebeu uma bolsa de estudos do governo belga (OCD) para iniciar seus estudos de Pós-Graduação na Universidade Católica de Louvain, Bélgica, onde permaneceu de 1969 a 1971. Nesse tempo, foi pesquisador no Museu Real da África Central em Tervuren (Bruxelas) onde se especializou em estudo das artes africanas tradicionais. No entanto, por questões relacionadas à ditadura militar instalada em seu país, teve que voltar sem terminar o doutorado. Entre os anos de 1975 a 1977, com bolsa concedida pela Universidade de São Paulo, conclui seu doutorado na USP, em Ciências Humanas (área de concentração em Antropologia Social). Foi professor visitante na Escola de Sociologia e Política de São Paulo (1977), na Universidade Candido Mendes (1977), na Universidade Federal do Rio Grande do Norte, em Natal (1979-1980), na Universidade Eduardo Mondlane, em Maputo, Moçambique(1999), professor associado na Universidade de Montreal, Canadá (2005-2010), onde ministrou seminários além de orientar projetos de mestrado e teses de doutoramento na Faculdade da Ciência das religiões. Fez a maior parte de sua carreira acadêmica como professor efetivo na Universidade de São Paulo, de 1980-2012, de onde se aposentou como Professor Titular, atuando principalmente nas áreas de Antropologia da África e da População Afro-brasileira, com enfoque nos seguintes temas: racismo, políticas e discursos antirracistas, negritude, identidade negra versus identidade nacional, multiculturalismo e educação das relações étnico-raciais. Organizou o livro "Superando o racismo na escola", que foi o primeiro a introduzir a questão racial nos temas transversais dos Parâmetros Curriculares Nacionais, livro cujas primeira e segunda edições foram prefaciadas respectivamente pelo ministro da Educação Nacional Paulo Renato e pelo então Presidente da República, Fenando Henrique Cardoso. Ocupou cargos de Diretor do Museu de Arqueologia e Etnologia da Universidade de São Paulo (1983-1989), Vice-Diretor do Museu de Arte Contemporânea da Universidade de São Paulo (2002-2006), Diretor do Centro de Estudos Africanos da Universidade de São Paulo (2006-2010). É autor de mais de 150 publicações entre livros, capítulos de livros e artigos científicos. Recebeu vários prêmios e títulos honoríficos, entre os quais: a Comenda da Ordem do Mérito Cultural, pela Presidência da República Federativa do Brasil (2002); Grau de Oficial da Ordem do Rio Branco do Ministério das Relações Exteriores, Palácio do Itamaraty (2013); Prêmio Benedito Galvão, da Ordem dos Advogados do Estado de São Paulo (2012); Troféu Raça Negra 2012, pelo Afro-Brás e Faculdade Zumbi dos Palmares (2011); Homenagem como Decano em Estudos Antropológicos, pelo Departamento de Antropologia da USP (2008); Homenagem da Associação dos Docentes da Universidade de São Paulo, ADUSP, em 2012, entre outros. Foi um dos protagonistas intelectuais negros no debate nacional em defesa das cotas e políticas afirmativas. Em setembro de 2016 recebeu o título de cidadania baiana pela Assembleia Legislativa do Estado da Bahia. Foi professor visitante sênior da Universidade Federal do Recôncavo da Bahia - UFRB, através de uma bolsa da CAPES. Em 29 de junho de 2018, recebeu o Prêmio de Direitos Humanos USP/2017. Em 2020, recebeu o título de Doutor Honoris Causa na UFRJ.
} 
frequentadas por cidadãs e cidadãos brasileiros de todas as cores. A questão que se coloca é saber como conseguiram resistir, sobreviver para se tornarem um dos patrimônios culturais brasileiro, cubano, haitiano, colombiano, venezuelano, entre outros. Onde estaria escondido o segredo dessa resistência, que surpreende o mundo diante de tanta força opressiva e destruidora pela qual passaram os africanos escravizados e seus descendentes de hoje? Tudo deixa crer que, apesar da violência da qual foram vítimas, eles não abriram mão da defesa de sua dignidade humana, de sua liberdade e identidade.

Palavras-chave: discriminação religiosa; racismo; religiões de matriz africana.

Abstract: The objective of this article is to make a critical reflection on the violence that permeates the trajectory of the black population in Brazil, from the transatlantic human trafficking to the present day, having as main focus the religious discrimination embedded in Brazilian racism way, which impacts the African-based religions in different contexts, making them the target of persecutions and campaigns of destruction. Surprisingly, these religions resisted, survived and became Brazilian religions accepted and frequented by Brazilian citizens of all colors. The question that arises is how they managed to resist, survive to become one of the Brazilian cultural patrimonies, Cuban, Haitian, Colombian, Venezuelan cultural heritage, among others. Where would the secret of this resistance be hidden, which surprises the world in the face of so much oppressive and destructive force that the African slaves and their descendants of today went through? Everything indicates that, despite the violence they were victims of, they did not abandon the defense of their human dignity, their freedom and their identity.

Keywords: religious discrimination; racism; African-based religions.

Conferência Religiōes de Matriz. Africana e Intolerância Religiosa, proferida na Solenidade de Inauguração da sede do Núcleo de Estudos Afro-Brasileiros da Universidade Estadual de Londrina (NEAB-UEL), nomeado Casa Dona Vilma - Yá-Mukumby, em homenagem a Vilma Santos de Oliveira, valorosa liderança do Movimento Negro e da luta por Ações Afirmativas na UEL. O evento ocorreu no dia 26 de julho de 2018 no Anfiteatro Maior do CLCH, promovido pelo Núcleo de Estudos Afro-Brasileiros e pelo Laboratório de Cultura e Estudos Afro-Brasileiros (LEAFRO), coordenados pela Prof. ${ }^{a}$ Dr. ${ }^{a}$ Maria Nilza da Silva.

Imaginemos as cenas de violência e horror que aconteceram cerca de quatrocentos anos atrás, quando milhões de homens, mulheres e jovens africanas e africanos começaram a ser transportados(as) para as Américas através do tráfico humano transatlântico. Eles foram sequestrados, acorrentados e embarcados nos tumbeiros ou navios negreiros, sem saber por que motivos estavam sendo transportados e para onde estavam sendo levados. Não eram tratados como seres humanos, mas sim como mercadorias vivas, um negócio lucrativo para os traficantes. Além de mercadoria, serviram também como força animal de trabalho nas plantações de cana de 
açúcar, de algodão e nas minerações, com o fim de produzir riquezas para a construção da economia colonial. Riquezas produzidas ao preço de suor e sangue, de tortura e de várias formas de violências inimagináveis.

Milhões deles morreram na travessia transatlântica, de fome, maus tratos e até de banzo. Outros não aguentaram as humilhações e preferiram se suicidar, afogando-se no atlântico. A bordo dos tumbeiros havia capelas onde foram batizados para iniciar o processo de sua conversão ao cristianismo, de acordo com as recomendações do Vaticano, pois era preciso salvar suas almas, mesmo deixando morrer seus corpos.

Quero dizer que o processo de destruição das religiões de matriz africana começou cedo, antes dos portadores dessas religiões pisarem nas terras de destino. Pelo batizado, seus nomes étnicos foram substituídos pelos nomes europeus do calendário cristão, o que marcou o início do processo de destruição de suas identidades étnico-culturais simbolizadas pelos nomes originais. Durante a travessia transatlântica, eles já eram proibidos de cultuar seus deuses. Chegando à terra de destino, o processo de destruição de suas identidades religiosas radicalizou-se drasticamente pela implantação de leis e proibições policiais. Esses milhões de pessoas foram arrancados pela força de suas raízes culturais e religiosas e deportados para um universo cultural e religioso estranho.

Diante do rolo compressor da escravidão, que teria como resultado desenraizá-lo totalmente, o resultado final esperado teria sido a perda total de sua identidade cultural e religiosa e de sua memória histórica. Surpreendentemente, essas religiões resistiram, sobreviveram e se tornaram religiões brasileiras aceitas e frequentadas por cidadãs e cidadãos brasileiros de todas as cores. A questão que se coloca é saber como conseguiram resistir, sobreviver para se tornarem um dos patrimônios culturais brasileiro, cubano, haitiano, colombiano, venezuelano, entre outros. Onde estaria escondido o segredo dessa resistência, que surpreende o mundo diante de tanta força opressiva e destruidora pela qual passaram os africanos escravizados e seus descendentes de hoje? Tudo deixa crer que, apesar da violência da qual foram vítimas, eles não abriram mão da defesa de sua dignidade humana, de sua liberdade e identidade.

O núcleo duro dessa resistência foi sua religião por onde passa sua visão do mundo, da natureza, do cosmos, ou seja, sua visão global da existência. Visão que costura as relações entre os seres humanos e o mundo animal e vegetal, entre povos e nações, entre povos e o Criador supremo que existe em todas as culturas e sociedades africanas certamente com nomes diferentes, de acordo com a diversidade linguística continental. Eles não abriram mão de suas religiões cuja relação dialógica com a estrutura política, econômica e social é fundamental. Por isso, a religião constitui 
o núcleo duro, a partir do qual se organizou a resistência cultural afro-brasileira em outros setores da vida: artes, música, dança, culinário, plantas medicinais, entre outros.

Mas, como isso foi possível diante das relações assimétricas de poder entre escravizados e senhores donos das fazendas e engenhos, seus escravizadores? Os escravizados não podiam enfrentar frontalmente seus "senhores" por causa da desigualdade entre as forças: pois uns tinham capatazes e armas de fogo, e outros tratados como animais estavam desarmados. Eles descobriram uma saída ao desenvolver uma estratégia, muito inteligente de relacionamento entre forças desiguais, que consistiu em driblar os obstáculos sem enfretamento físico frontal. Descobriram que havia semelhanças entre as características dos santos católicos e as de algumas de suas divindades, Orixás ou Inkissi, que adotaram como seus protetores ou correspondentes para proteger seus próprios santos da violência dos opressores, numa espécie de convivência e cumplicidade harmoniosas. Assim, quando havia batidas policiais nos barracões, os opressores encontravam ali figuras de santos católicos, altares e velas acesas. Saíam tranquilamente, acreditando que eles estavam cultuando santos católicos, enquanto os assentamentos de seus orixás estavam escondidos em algum lugar nesse espaço de convívio de diversidades não proclamado. Além de conviver pacificamente com o Deus e santos cristãos, os africanos e seus descendentes escravizados abriram também em seus terreiros, o espaço de convivência com os deuses da terra, os chamados caboclos que eles começaram a cultuar para construir também com eles uma relação pacífica entre forças vitais originárias da terra "Brasil" e eles estranhos deportados, pois os caboclos não eram conhecidos na África.

Tudo isso foi chamado sincretismo religioso pelos estudiosos das religiões africanas no Brasil. Sem dúvida, os sangues se misturaram, os deuses se tocaram e as cercas das identidades vacilaram, mas tem de ficar claro que não se trata de síntese no sentido de uma nova religião nascida dos contatos entre religiões de matriz africana e religiões cristãs. Trata-se de um pluralismo religioso caracterizado pelas trocas simbólicas e convivência pacífica num mesmo espaço social e geográfico. Como disse o Babalorixá Balbino de Apó Afonjá em Salvador, o Candomblé e o catolicismo são como a água e o óleo que, misturados na mesma bacia, ficam ali tranquilamente, mas em camadas separadas. Nada de síntese no sentido de $A$ mais $B$ igual $C(A+B=C)$; nada de caldeirão, mas simplesmente uma justaposição na mesma bacia. Assim, os Ibeji se aproximaram dos santos Cosme e Damião; Oxalá de Jesus ou Nosso Senhor do Bonfim; Yemanjá de Nossa Senhora da Conceição; Xangô de São Pedro; Oxossi de São Jorge; Obaluaé de São Lázaro, entre outros.

Uma outra característica das religiões de matriz africana é a de não serem religiões proselitistas ou universalistas responsáveis por muitos conflitos na história da humanidade. Creio 
que todo mundo se lembra da história das inquisições na Península Ibérica, nos séculos XIV e XV; das guerras santas islâmicas ou Jihad; das cruzadas; dos conflitos entre ortodoxos, católicos e muçulmanos em Kosovo; dos conflitos entre católicos e protestantes na Irlanda do Norte. Mas não temos registros históricos sobre conflitos religiosos na África tradicional, a não ser os conflitos entre religiões universalistas importadas para a África, como os que têm ocorrido na Nigéria entre o Sul católico e o Norte islâmico e que desestabilizam o processo de construção de paz e até a estrutura política daquele país. A explicação estaria no fato das religiões tradicionais africanas terem um caráter familial e não universalista em busca da clientela. São religiões que sabem integrar os diversos e os diferentes num quadro familial de convivência, sem hierarquização entre homens e mulheres, pois as mulheres e os homens têm o mesmo estatuto pleno de sacerdote. Ou seja, um babalorixá, ou pai de santo, e uma Ialorixá, ou mãe de santo, são iguais em seus estatutos de sacerdote. Heterossexuais e homossexuais convivem como irmãos e irmãs sem exclusão homofóbica existente em outras religiões do mundo. Políticos de todas as tendências ideológicas, que às vezes se apresentam durante as campanhas eleitorais em busca de votos, são recebidos igualmente nos terreiros de candomblé ou de Umbanda, pelo que já observei pessoalmente.

Mas, uma coisa posso arriscar-me a afirmar, a saber, que os espaços de cultos religiosos de matriz africana não são reservas eleitorais de alguns partidos políticos, porque essas religiões têm uma certa neutralidade partidária. No entanto, sua clientela é cobiçada pelas religiões neopentecostais ou evangélicas por interesses econômicos e políticos. Daí, todas as perseguições e campanhas de destruição, que demonizam e satanizam essas religiões. O que muitos chamam de intolerância religiosa eu preferiria chamar de discriminação religiosa embutida no racismo à brasileira. Soube que, em algumas cidades do Brasil, terreiros de candomblé já foram incendiados na calada da noite por criminosos que fogem para não serem identificados. Estratégias que o Movimento Ku Klux Klan usava no sul dos Estados Unidos contra habitações das comunidades negras. Soube que o acarajé, comida de origem religiosa considerado patrimônio cultural brasileiro, está sendo chamado bolinho de jesus por essas religiões destruidoras das religiões de matriz africana. Não sei se Jesus, nascido palestino e que foi arianizado na iconografia universal, comia acarajé. Talvez pudesse gostar, mas não foi bolinho dele.

Tolerar, quando referido a pessoas que ocupam posição superior, significa admitir que pessoas que ocupam posição inferior possam ter a liberdade de cultuar seus deuses. O que os excluídos, os oprimidos e os discriminados podem tolerar da parte de pessoas que querem ditar a outrem as regras de jogo e de comportamento? O que os pobres, miseráveis e explorados podem tolerar da parte de pessoas ricas e burguesas? Portanto, eu sempre considero as palavras tolerar e 
não-tolerar impróprias, pois ninguém luta, trabalha e constrói para ser tolerado por outro, mas para ser, no mínimo, respeitado e tratado igualmente no que concerne aos direitos humanos fundamentais, entre os quais se incluem as liberdades de crenças, cultos e religião. O que as religiões de matriz africana sofrem hoje, no Brasil, não é a intolerância em si, é uma discriminação racial que visa sua eliminação total do universo religioso brasileiro que é por definição plural. É um crime inominável que deve ser combatido e condenado pelas leis do país.

Aqui se coloca a responsabilidade do estado brasileiro num estado de direito. Um estado laico é neutro religiosamente, pois não há religião do Estado como aconteceu e acontece em alguns países do mundo. Mas, ser neutro não significa ser indiferente a discriminações e conflitos religiosos, pois o Estado tem obrigação, determinada nas leis do país, de garantir a todos os cidadãos liberdade de crença, culto e religião, que fazem parte dos diretos fundamentais contidos na Declaração Universal dos Diretos Humanos, sem tomar partido. Nesta casa que nos reúne há pessoas mais qualificadas que eu para falar e analisar detalhadamente as responsabilidades do Estado brasileiro neste assunto. Por isso vou fugir deste campo para me deter em outros aspectos que dizem respeito à especificidade das religiões de matriz africana no Brasil.

A religiosidade, termo derivado de religião, tem primeiramente a ver com as relações de devoção que os seres humanos de diversas culturas mantêm com os seres sobrenaturais, deuses, ancestrais e outras forças da natureza. Trata-se de um sentimento que transborda o conteúdo de uma religião específica para permear outros aspectos do complexo cultural ao qual pertence uma religião. No que diz respeito às sociedades africanas, observa-se que, além de sua rica diversidade, o sentimento de religiosidade impregna os comportamentos em todos os domínios da cultura. E, nesse sentido, é um dado da africanidade que existe não apenas no continente-mãe, mas também em toda sua diáspora onde a religião representou o núcleo mais duro de sua resistência e em torno do qual se reestruturam outros setores de vida no novo mundo.

Começando pela relação com a natureza, os povos africanos estabelecem uma rigorosa hierarquia entre as forças: no topo está o Deus único, não-criado e criador, aquele que dá força e potência por ele mesmo. Ele dá existência, substância e acréscimo às outras forças. Depois dele vêm os antepassados divinizados ou orixás, fundadores dos clãs. Abaixo encontram-se os vivos que, por sua vez, são ordenados segundo a lógica genealógica na qual os mais velhos têm primazia sobre os mais jovens. No plano paralelo vêm os animais, as plantas e os minerais. A ética africana consiste, portanto, no reconhecimento da unidade do mundo e do agir para manter o equilíbrio das forças, da ordem e estabilidade. Dessa concepção deriva a ideia do sagrado, fulcro de toda a vida africana, onde cada ser, cada coisa, possui uma força vital de energia divina. O ser humana 
está ligado à planta, ao animal, aos seres semelhantes vivos e mortos, ao cosmos através do ritmo vital, e ao deus através do sacrifício ritual. Segundo Senghor, a religião africana está centrada no sacrifício, que determina a comunhão dos vivos e dos mortos, porque a força vital do animal sacrificado flui, através do sacrifício em direção ao antepassado e deste, de novo, em direção à comunidade que ele encarna. Aqui está o fundamento do sacrifício dos animais nas religiões brasileiras de matriz africana como o Candomblé que hoje está sendo combatido pelos detratores dessas religiões. As toneladas de carnes que a humanidade inteira consome vêm dos animais matados, mas matados em circunstâncias cerimoniais religiosas às quais me referi não podem. Por que sancionar leis só às religiões de matriz africana e não à humanidade inteira, que se alimenta da carne dos animais mortos, ou seja, sacrificados?

Os antepassados e os mortos são intermediários entre o ser humano e Deus. Pela sua concepção animista, o africano faz da terra uma pessoa, um gênio. $O$ antepassado étnico, o primeiro cultivador e ocupante da terra, fez com este gênio um pacto, celebrado pelo sacrifício ritual. Este pacto não foi feito em nome pessoal, mas em nome de toda a comunidade que ele encarna. A família, a povoação, o grupo, não são, portanto, proprietários da terra, mas apenas beneficiários. Por isso, a terra é um patrimônio social sagrado e inalienável. Nas poesias inspiradas pela caça, o caçador não se orgulha das suas proezas em relação à presa, ele exprime simplesmente louvor e respeito, pois o caçador e a presa desempenham os mesmos papéis no drama da existência. Por conseguinte, a natureza não é um inimigo que se tem de vencer a qualquer preço. $O$ africano sente-se parte integrante da natureza, e sua ação inscreve-se num sistema de relações com o cosmos, com as plantas, com os animais e num sistema de relações sociais. Por isso, ritos e ações, nas religiões de matriz africana, não existem sem o apoio da natureza, das plantas e das folhas como se diz e sem os sacrifícios dos animais. Tudo isso são valores específicos que pertencem a essas religiões, também outras religiões têm seus valores a serem respeitados. São caminhos diferentes para chegar aos deuses, pois não existem sociedades sem crenças e religiões e vice versa. Mas, por que os caminhos conflitam? São os próprios deuses que exigem que os humanos conflitem como se não fossem capazes de se defender contra as ações humanas? As religiões conflitam porque são imbuídas de ideologia, de interesses políticos e econômicos, daí a busca de uma numerosa clientela para sustentá-la. É preciso encontrar um bode expiatório e as religiões de matriz africana servem por isso. Como os detentores dessas religiões não possuem meios de comunicação de massa para veicular suas propagandas religiosas em busca da clientela; como não têm uma bancada no Congresso Nacional para defender seus projetos, que são de caráter familial; como não têm contas em bancos no exterior e no país, nem força suficiente para defender os homossexuais, vítimas da 
homofobia, e os negros e as negras, vítimas do racismo, eles podem ser destruídos sistematicamente, se a sociedade civil consciente não acordar e se o Estado não tomar suas responsabilidades, que são próprias de um Estado de direito. Quem perderá não serão eles, pois os mortos não perdem nada, já que estão mortos. Quem perderá vai ser a sociedade brasileira e a humanidade inteira. A diversidade em todos os sentidos, seja ela a da emoção ou a da razão, das culturas, das línguas e religiões constitui a riqueza coletiva da humanidade.

Levou muitos anos para que as religiões brasileiras de matriz africana pudessem ser reconhecidas oficialmente como religiões entre as outras que constituem o universo religioso brasileiro que é plural. Foram anos de resistência, como já disse, que exigiu estratégias inteligentes diante da desigualdade das forças. No início do século XXI, os fiéis dessas religiões, de todas as cores e de ambos os sexos, brancos, negros, mestiços, poderiam ter pelo menos o direito de relaxar. Infelizmente, devem ainda enfrentar as novas ondas de preconceito e discriminação religiosa que a literatura chama de intolerância religiosa. O que eles fizeram contra a sociedade brasileira, ou seja, contra a humanidade para merecer essa campanha de destruição e aniquilamento? Alguém já ouviu os fiéis dessas religiões ou seus sacerdotes fazerem a campanha de difamação contra as outras religiões? Mas, por que tanto ódio contra eles? Porque por trás têm interesses em jogo; interesses políticos, econômicos e financeiros. É preciso aumentar a clientela que paga o dízimo; é preciso aumentar a reserva eleitoral para a bancada política que defende seus interesses; é preciso ter a maioria para oprimir a homossexualidade, o aborto e outras propostas que eles consideram como contra as leis sagradas. A sociedade brasileira tem de lutar contra isso antes que seja tarde demais. Os extremismos religiosos soltos em outros países do mundo não tardarão a infernizar este país cuja diversidade cultural e religiosa constitui sua maior riqueza.

Finalmente, coloca-se a questão de saber como e por que esses valores civilizatórios, que pertencem à ancestralidade de uma África em plena evolução cultural, uma África que não existe mais hoje, podem servir de referência para educação brasileira? Num mundo globalizado, onde os jovens de todas as sociedades contemporâneas estão conectados à internet e às redes sociais, para que serviria uma educação baseada numa ancestralidade longínqua e divorciada de seus interesses materiais e espirituais?

No entanto, a questão de saber quem somos, de onde viemos, por onde estamos indo e para onde vamos se coloca cada vez mais frequente e insistentemente no mundo de hoje, apesar da globalização homogeneizante. Ela tem a ver com o processo de construção das identidades coletivas cujo vínculo com os valores ancestrais são necessários, conquanto não os vivamos. 
A ancestralidade brasileira é múltipla. Ela é indígena, europeia, africana e asiática, pois remete a todas as raízes culturais formadoras do Brasil de hoje. A crítica ao modelo de uma educação eurocêntrica e a busca de uma educação pluricultural inclusiva, que tem a ver com a rica diversidade brasileira, convidam ao resgate de raízes culturais da ancestralidade africana e indígena que foram rechaçadas pela educação dominante. Daí a necessidade de reinventar o passado para entender o presente e projetar o futuro.

Como cidadã e cidadão, cada um e cada uma de nós tem o direito de praticar e viver a religião que escolheu como a melhor para nos ajudar a lidar com os problemas vivenciais, mas não temos o direito de odiar, difamar e destruir a religião dos outros.

Acorda, Brasil! 